\section{THU0676 A SYSTEMATIC REVIEW AND META-ANALYSIS OF VIRAL EXPOSURES AS A RISK FACTOR FOR RHEUMATOID ARTHRITIS}

F. Kudaeva ${ }^{1}$, M.R. Speechley ${ }^{2}$, J.E. Pope ${ }^{3} .{ }^{1}$ Epidemiology and Biostatistics; ${ }^{2}$ Epidemology and Biostatistics, Schulich School of Medicine and Dentistry, Western University; ${ }^{3}$ Division of Rheumatology, St. Joseph's Health Care, Schulich School of Medicine and Dentistry, London, Canada

Background: Rheumatoid arthritis (RA) is an autoimmune disease with a complex and poorly understood etiology. Development of autoimmune disease stems from a combination of immune, genetic, hormonal and environmental factors. Infections are viewed as triggers of some autoimmune disorders, including RA. Objectives: Different viral exposures have been implicated in the etiology of RA via several mechanisms of immune activation, such as molecular mimicry. The purpose of this systematic review was to summarise the evidence relating to the association between putative viral exposures and the development of RA

Methods: A systematic literature search was conducted using MEDLINE-OVID, EMBASE-OVID, PUBMED and Cochrane library databases. Articles were included if they were case-controls, cross-sectional or cohort studies and were published in English. Case-series were included if there was a lack of other study designs.

Results: Of 6724 citations, 78 studies were selected for review, and 48 were included in meta-analysis. Studies had poor quality. Based on the $\lg G$ antibodies ( $n=12$ studies) and viral DNA detection ( $n=3$ studies), the odds of parvovirus B19 (PBV19) infection were increased in RA patients than in controls (odds ratio (OR) $(95 \% \mathrm{Cl})=1.77(1.11 ; 2.80), \mathrm{p}=0.02$, OR $(95 \% \mathrm{Cl})=3.53 \quad(1.00 ; 12.53)$, $\mathrm{p}=0.05$ for $\mathrm{PVB} 19 \mathrm{lgG}$ and DNA, respectively). For Epstein-Barr virus (EBV), patients with RA had not significant $\mathrm{OR}$ of anti-Epstein-Barr nuclear antigen (EBNA) ( $\mathrm{n}=17$ studies, OR $(95 \% \mathrm{Cl})=1.05(0.79 ; 1.39), \mathrm{p}=0.75)$, but significant OR of anti-viral capsid antigen (VCA) $(n=18$ studies, OR $(95 \% \mathrm{Cl})=1.5(1.07$; 2.10), $\mathrm{p}=0.02)$ and anti-early antigen ( $E A)(n=11$ studies, $O R(95 \% \mathrm{Cl})=2.74$ $(1.27 ; 5.94), p=0.01)$. Cytomegalovirus (CMV) was not associated with RA ( $n=13$ studies, OR $(95 \% \mathrm{Cl})=1.24(0.78 ; 1.95), p=0.36)$. Chronic hepatitis B (HBV) was not associated with RA in 5 case-control $(\mathrm{OR}(95 \% \mathrm{Cl})=1.37(0.83 ; 2.25$, $\mathrm{p}=0.22)$ and 1 cohort studies (HR $1.09(0.74,1.63), p>0.05)$. Chronic hepatitis $C$ (HCV) was associated with increased risk of RA in 7 case-control (OR $195 \%$ $\mathrm{Cl}=2.82(1.35 ; 5.90, \mathrm{p}=0.006)$ and 1 cohort studies (HR 2.03 (1.27, 3.22), $\mathrm{p}<0.01)$. There seem to be a risk of persistent arthritis after Chikungunya fever (CHIKV) $(n=2$ studies, OR $(95 \% \mathrm{Cl})=90(15.2 ; 134.3)$.

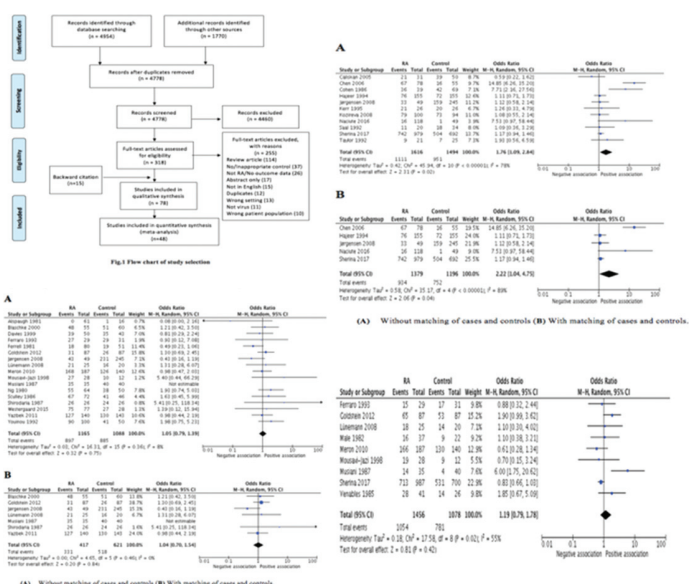

Abstract THU0676 - Figure 1. Flow chart of study selection. Abstract THU0676 - Figure 2. Forest plots for cumulative odds ratio $(95 \% \mathrm{Cl})$ of serum lgG anti-PVB19 antibodies in RA cases and controls. (A) Without matching of cases and controls (B) With matching of cases and controls.. Abstract THU0676 - Figure 3. Forest plot for cumulative odds ratio (95\% Cl) of serum anti-EBNA IgG in RA cases and controls. (A) Without matching of cases and controls (B) With matching of cases and controls. Abstract THU0676 - Figure 4. Forest plot for cumulative odds ratio $(95 \% \mathrm{Cl})$ of serum anti-CMV IgG in RA patients and controls.

Conclusions: Studies about the risk of RA after viral exposures suffer from inconsistent methodological quality. There is a risk of RA after Parvo B19 infection and possibly HCV but not EBV or HBV. There seems not to be a risk of RA after EBV infection. CHIKV is associated with the persistent inflammatory arthritis. There is not enough evidence to support an association between some viruses and RA development, but they probably lead to RA in genetically susceptible individuals. Disclosure of Interest: None declared DOI: 10.1136/annrheumdis-2018-eular.2202

\section{THU0677 \\ PNEUMOCOCCAL ANTIBODY PROTECTION IN RHEUMATOLOGICAL PATIENTS RECEIVING BDMARD THERAPY - A CROSS-SECTIONAL STUDY}

S. Rasmussen ${ }^{1}$, K. Fuursted ${ }^{2}$, K. Nielsen ${ }^{1}$, N. Parks ${ }^{1}$, M. Sørensen ${ }^{3}$, P. Leutscher ${ }^{3}$, C. Rasmussen ${ }^{4} .{ }^{1}$ Regional Hospital North Jutland, Hiørring;

${ }^{2}$ Statens Serum Institut, Copenhagen; ${ }^{3}$ Center for Clinical Research; ${ }^{4}$ Department of Rheumatology, Regional Hospital North Jutland, Hjørring, Denmark

Background: Severe pneumococcal infections contribute to increased mortality in patients with rheumatic diseases, and is preventable by vaccination against Streptococcus pneumoniae. EULAR recommends that pneumococcal vaccination should be strongly considered in patients with rheumatic diseases, however need and timing of revaccination for this patient group remains unknown ${ }^{1}$. Since 2009, rheumatological patients from our department have been vaccinated against $S$. pneumoniae prior to initiation of bDMARD therapy, by use of the 23-valent pneumococcal polysaccharide vaccine (PPV23). To our knowledge, we are the only centre in Denmark to vaccinate these patients routinely.

Objectives: The aim of the study was to determine the prevalence of rheumatological patients receiving bDMARD therapy with a protective level of antibodies against $S$. pneumoniae, and to identify possible factors of relevance affecting antibody production.

Methods: Antibodies against 12 pneumoccocal serotypes were measured in the period of June to December 2017 in patients receiving bDMARD therapy initiated before March 1st 2017. A geometric mean level of all serotypes above $1 \mu \mathrm{g} / \mathrm{ml}$ was considered a protective antibody level. The patients had been diagnosed with rheumatoid arthritis, spondyloarthritis, psoriatic arthritis or juvenile idiopathic arthritis. The study group consisted of both vaccinated and unvaccinated individuals, where unvaccinated individuals initiated bDMARD therapy before vaccination occurred routinely.

Differences in protection between vaccinated and unvaccinated patients were evaluated using the $\chi^{2}$ test. We included the following variables in a logistic regression model, to analyse factors of possible significance to the protective level of antibodies: age, sex, diagnosis, methotrexate (MTX) and/or prednisolone treatment at time of vaccination, and years since vaccination.

Results: A total of 319 patients were included in the study: 186 (58\%) vaccinated and $133(42 \%)$ unvaccinated patients. Among the vaccinated patients, 30\% had a protective antibody level versus $0 \%$ of the unvaccinated patients $(p<0.0001)$.

Logistic regression analysis showed that a significantly smaller proportion of patients treated with MTX at time of vaccination had a protective antibody level compared with patients not treated with MTX ( $\mathrm{p}=0.03$; odds ratio: $2.3 ; 95 \% \mathrm{Cl}$ $[1.1 ; 4.7])$. The same applied for advanced age at time of vaccination $(p=0.04)$, whereas years since vaccination did not decrease antibody protection significantly $(p=0.12)$

Conclusions: Only one third of PPV23 vaccinated rheumatological patients treated with bDMARD were observed with a GML of pneumococcal antibodies above $1 \mu \mathrm{g} / \mathrm{ml}$. This suggests that a majority of these patients are not protected adequately against pneumococcal disease in spite of vaccination. MTX treatment at time of vaccination and advanced age were both independently associated with lack of protective antibody level.

\section{REFERENCE:}

[1] van Assen S, Agmon-Levin N, Elkayam O, et al. EULAR recommendations for vaccination in adult patients with autoimmune inflammatory rheumatic diseases. Ann Rheum Dis 2011;70(3):414-422.

Disclosure of Interest: None declared DOI: 10.1136/annrheumdis-2018-eular.3657

\section{THU0678 TREND OF VENOUS THROMBOEMBOLISM AMONG SELECT RHEUMTOLOGIC DISEASES: AN AUDIT OF LARGE NATIONAL US DATABASE}

D.R. Poudel ${ }^{1}$, R. Dhital ${ }^{1}$, P. Paudel ${ }^{2}$, S. Basnet ${ }^{1}$, P. Sharma ${ }^{1}$, P. Shrestha ${ }^{1}$, P. Karmacharya ${ }^{1,3} .{ }^{1}$ Internal Medicine, Tower Health System, Reading Hospital, West Reading; ${ }^{2}$ Internal Medicine, Berkshire Medical Center, Pittsfield; ${ }^{3}$ Division of Rheumatology, Mayo Clinic, Rochester, USA

Background: Venous thromboembolism (VTE) is 3rd commonest cause of cardiovascular deaths and encompasses deep-venous thrombosis (DVT) and pulmonary embolism (PE). Rheumatologic diseases have been found to be associated with an increased risk of VTE among hospitalised patients.

Objectives: To describe the trend of VTE among select rheumatologic diseases over 15 years.

Methods: We used National Inpatient Sample (NIS) database for years 20002014 to identify adults $\geq 18$ years with select rheumatologic diseases and VTE based on ICD-9 codes. Prevalence was age-sex adjusted against US census population data. STATA was used for querying database and Joinpoint regression 


\begin{tabular}{|c|c|c|c|c|c|c|c|c|c|c|}
\hline & Totals & Controls & RA & SLE & Sicca/Sjogren's & Scleroderma & Spondyloarthropathies & DM/PM & Vasculitides & VTE \\
\hline \multicolumn{11}{|c|}{ Counts (\% of hospitalizations) } \\
\hline Overall & $\begin{array}{c}461089203 \\
(100)\end{array}$ & $\begin{array}{c}451761667 \\
(97.98)\end{array}$ & $5609502(1.22)$ & $1980776(0.43)$ & $274106(0.06)$ & $335926(0.07)$ & $436702(0.09)$ & $\begin{array}{c}182420 \\
(0.04)\end{array}$ & $508104(0.11)$ & $\begin{array}{c}8822456 \\
(1.91)\end{array}$ \\
\hline $\begin{array}{l}2000 / \\
2002\end{array}$ & $\begin{array}{c}89251049 \\
(100)\end{array}$ & $\begin{array}{c}87822413 \\
(98.4)\end{array}$ & $829687(0.93)$ & $324117(0.36)$ & $32618(0.04)$ & $60004(0.07)$ & $56851(0.06)$ & $32495(0.04)$ & $92863(0.1)$ & $\begin{array}{c}1292852 \\
(1.45)\end{array}$ \\
\hline $\begin{array}{l}2003 / \\
2005\end{array}$ & $\begin{array}{l}92374203 \\
(100)\end{array}$ & $\begin{array}{c}90738381 \\
(98.23)\end{array}$ & $950197(1.03)$ & $374136(0.41)$ & $40013(0.04)$ & $66331(0.07)$ & $67450(0.07)$ & $36482(0.04)$ & $101213(0.11)$ & $\begin{array}{c}1582058 \\
(1.71)\end{array}$ \\
\hline $\begin{array}{l}2006 / \\
2008\end{array}$ & $\begin{array}{c}95006960 \\
(100)\end{array}$ & $\begin{array}{c}1847533 \\
(98.05)\end{array}$ & $28589(1.16)$ & $14668(0.43)$ & $1334(0.05)$ & $1745(0.07)$ & $2126(0.09)$ & $1536(0.04)$ & $4302(0.11)$ & $1901832^{2}$ \\
\hline $\begin{array}{l}2009 / \\
2011\end{array}$ & $\begin{array}{c}94195026 \\
(100)\end{array}$ & $\begin{array}{c}1961465 \\
(97.73)\end{array}$ & $37829(1.4)$ & $14408(0.46)$ & $1903(0.08)$ & $1920(0.08)$ & $2619(0.11)$ & $1603(0.04)$ & $4767(0.11)$ & $\begin{array}{c}2026514 \\
(2.15)\end{array}$ \\
\hline $\begin{array}{l}2012 / \\
2014\end{array}$ & $\begin{array}{c}90261964 \\
(100)\end{array}$ & $\begin{array}{c}1948300 \\
(97.48)\end{array}$ & $40800(1.56)$ & $15635(0.5)$ & $2330(0.09)$ & $2145(0.08)$ & $3670(0.14)$ & $1630(0.04)$ & $4690(0.12)$ & $\begin{array}{c}2019200 \\
(2.24)\end{array}$ \\
\hline \multicolumn{11}{|l|}{ VTE\% } \\
\hline Overall & 1.91 & 1.89 & 2.62 & 3.38 & 2.65 & 2.58 & 2.49 & 3.89 & 4.08 & - \\
\hline $\begin{array}{l}2000 / \\
2002\end{array}$ & 1.45 & 1.43 & 2.1 & 2.98 & 2.65 & 1.96 & 1.89 & 3.17 & 3.29 & - \\
\hline $\begin{array}{l}2003 / \\
2005\end{array}$ & 1.71 & 1.7 & 2.34 & 3.35 & 2.09 & 2.56 & 2.03 & 3.57 & 3.85 & - \\
\hline $\begin{array}{l}2006 / \\
2008\end{array}$ & 2 & 1.98 & 2.59 & 3.63 & 2.64 & 2.55 & 2.58 & 4.09 & 4.19 & - \\
\hline $\begin{array}{l}2009 / \\
2011\end{array}$ & 2.15 & 2.13 & 2.88 & 3.35 & 2.69 & 2.65 & 2.6 & 4.14 & 4.45 & - \\
\hline $\begin{array}{l}2012 / \\
2014\end{array}$ & 2.24 & 2.21 & 2.89 & 3.48 & 2.9 & 3.12 & 2.84 & 4.39 & 4.5 & - \\
\hline Adjustec & odds of VTE & ssociation ( & alue, $95 \% \mathrm{Cl}$ ) & & & & & & & \\
\hline & - & 1 & $\begin{array}{c}1.24(<0.0001 \\
1.22-1.3)\end{array}$ & $\begin{array}{c}2.2(<0.0002 \\
2.17-2.3) \\
\end{array}$ & $\begin{array}{c}1.3(<0.0003 \\
1.28-1.4)\end{array}$ & $\begin{array}{c}1.4(<0.0004 \\
1.3-1.45)\end{array}$ & $1.3(<0.0005,1.2-1.33)$ & $\begin{array}{c}2(<0.0006, \\
1.9-2.2) \\
\end{array}$ & $\begin{array}{c}1.8(<0.0007 \\
1.76-1.9) \\
\end{array}$ & - \\
\hline
\end{tabular}

was used to analyse annual trends of prevalence in terms of annual percentage change (APC). Logistic regression with survey command was used to derive adjusted odds of VTE association for all years combined.

Results: We included a total of $461,089,203$ hospitalizations among which $8,822,456(1.91 \%$ ) had VTE (table 1). An upward trend in the prevalence of VTE (APCs 2.45-4.16) (and PE subset) was noted in most of the rheumatologic disease groups (figure 1). DVT, however, had a decreasing or non-significant increasing trend among most disease groups (data for DVT and PE not shown). The adjusted odds of VTE association was highest among SLE group (aOR=2.2, $\mathrm{Cl}=2.17-2.3)$ followed by $\mathrm{DM} / \mathrm{PM}(\mathrm{aOR}=2.0, \mathrm{Cl}=1.9-2.2)$ (table 1).

Table 1 Frequency counts of rheumatologic diseases and controls; prevalence of VTE and adjusted regression analysis of VTE association

Abstract THU0678 - Figure 1 Trend. of proportion of VTE by disease groups and controls (APCs with * are statistically significant trends)

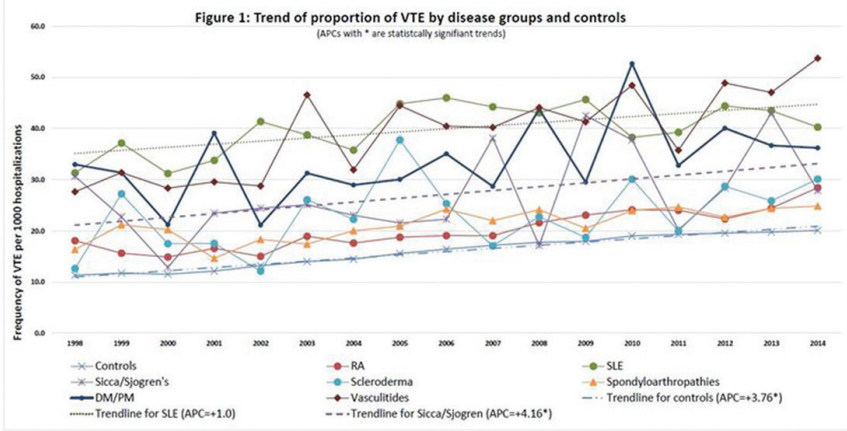

Conclusions: Inflammatory rheumatologic diseases seem to be associated with higher prevalence and odds of having VTE among hospitalised patients and the overall trend is rising. This might indicate some lag in following of guidelines for VTE prophylaxis. Closer look into the implications of stricter prophylaxis among rheumatologic patients is a matter of further studies.

Disclosure of Interest: None declared

DOI: 10.1136/annrheumdis-2018-eular.4499
THURSDAY, 14 JUNE 2018

Public health, health services research and health economics

\begin{tabular}{|l|l}
\hline THU0679 & INCREASED HOSPITALISATION RATES FOLLOWING \\
HEART FAILURE DIAGNOSIS IN RHEUMATOID \\
ARTHRITIS
\end{tabular}

E. Myasoedova ${ }^{1,1}$, J.M. Davis, III' ${ }^{1}$ S.J. Achenbach ${ }^{2}$, E.L. Matteson ${ }^{1}$ S. Setoguchi ${ }^{3}$, S.E. Gabriel ${ }^{4}$, C.S. Crowson ${ }^{2} .{ }^{1}$ Rheumatology; ${ }^{2}$ Health Sciences Research, Mayo Clinic College of Medicine, Rochester, MN; ${ }^{3}$ Rutgers School of Public Health; ${ }^{4}$ Rutgers Robert Wood Johnson Medical School, New Brunswick, NJ, USA

Background: There is a 2-fold increased risk of heart failure (HF) in rheumatoid arthritis (RA) compared to the general population. Little is known about hospitalisation rates in patients with RA and HF.

Objectives: We aimed to compare the frequency of and trends in hospitalizations after HF diagnosis in patients with and without RA during 1987-2015 and to assess risk factors for hospitalizations following HF in RA.

Methods: The study included a retrospectively identified population-based cohort of patients with incident HF and prior RA (age $\geq 18$ years, 1987 ACR criteria) and a cohort of incident HF patients without RA matched 3:1 on age, sex, and year of $\mathrm{HF}$ diagnosis. Hospitalizations at the time of HF diagnosis were excluded. All subjects were followed until death, migration, or 12/31/2015. Person-years methods and rate ratios (RR) from Poisson regression models were used to compare hospitalisation rates (number of hospitalizations divided by person-years of follow-up) between the groups. Conditional frailty models were used to examine risk factors for hospitalisation.

Results: The study included 212 patients with RA (mean age at HF diagnosis 78.3 years; $68 \%$ female) and 636 non-RA patients (mean age at HF diagnosis 78.6 years; $68 \%$ female). The hospitalisation rate after HF diagnosis was higher in RA vs non-RA (RR 1.16; $95 \% \mathrm{Cl} 1.08-1.25)$. This difference may be decreasing after 2010 (figure 1). The magnitude of the increase was similar in both sexes and across all ages. In a subset with available echocardiography ( $n=68$ RA and 449 non-RA), HF with preserved ejection fraction (HFpEF) was similarly prevalent in RA (57\%) vs non-RA (51\%; $p=0.3)$. Among those with HF with reduced ejection fraction (HFrEF) RA patients had more hospitalizations than non-RA subjects (RR 